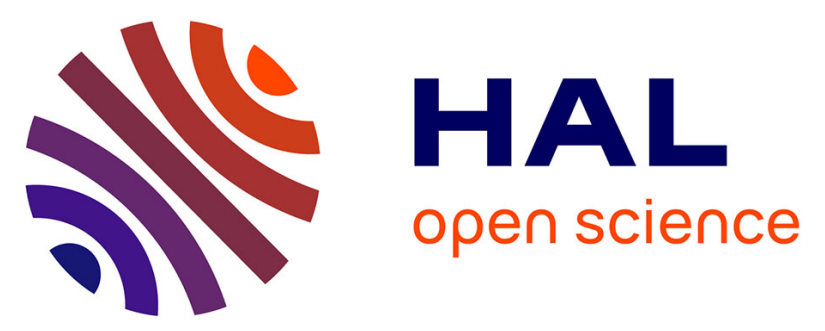

\title{
Simulation-Based Study About the Lifetime and Incident Light Properties Dependence of the Optically Triggered $4 \mathrm{H}-\mathrm{SiC}$ Thyristors Operation
}

Junichi Hasegawa, Loris Pace, Luong Viet Phung, Mutsuko Hatano, Dominique Planson

\section{To cite this version:}

Junichi Hasegawa, Loris Pace, Luong Viet Phung, Mutsuko Hatano, Dominique Planson. SimulationBased Study About the Lifetime and Incident Light Properties Dependence of the Optically Triggered 4H-SiC Thyristors Operation. IEEE Transactions on Electron Devices, 2017, 64 (3), pp.1203-1208. 10.1109/TED.2017.2657223 . hal-01636430

\section{HAL Id: hal-01636430 \\ https://hal.science/hal-01636430}

Submitted on 20 May 2019

HAL is a multi-disciplinary open access archive for the deposit and dissemination of scientific research documents, whether they are published or not. The documents may come from teaching and research institutions in France or abroad, or from public or private research centers.
L'archive ouverte pluridisciplinaire HAL, est destinée au dépôt et à la diffusion de documents scientifiques de niveau recherche, publiés ou non, émanant des établissements d'enseignement et de recherche français ou étrangers, des laboratoires publics ou privés. 


\title{
Simulation-based study about the lifetime and incident light properties dependency of the optically triggered $4 \mathrm{H}-\mathrm{SiC}$ thyristors operation
}

\author{
Junichi Hasegawa $^{1)}$, Loris Pace ${ }^{2)}$, Luong Viêt Phung ${ }^{2)^{*}}$, Mutsuko Hatano ${ }^{1)}$, and Dominique Planson ${ }^{2)}$ \\ 1) Tokyo Institute of Technology, 2-12-1 NE-18 Ookayama, Meguro-ku, Tokyo, Japan \\ 2) Université de Lyon, Ampère, INSA de Lyon, UMR CNRS 5005, F-69621 Villeurbanne, France. \\ * E-mail: luong-viet.phung@insa-lyon.fr
}

\begin{abstract}
We investigated a methodology to design light-triggered thyristors thanks to TCAD. The simulation model accuracy, especially the holding current and the minimum incident light intensity to turn-on, were compared with experimental results. The influence of $\mathrm{SiC}$ epitaxial layer lifetime and the incident light properties (wavelength and intensity) on the optically triggered $4 \mathrm{H}$-SiC thyristor characteristics have been studied by simulation. We considered the wavelength dependency of quantum efficiency, penetration depth and photon energy. The holding current and turn-on time depends on the lifetime. The minimum intensity to turn-on the device significantly depends on the wavelength. This intensity becomes less than 0.003 times when the wavelength changed from $380 \mathrm{~nm}$ to $325 \mathrm{~nm}$. In addition, the breakover voltage is affected by the constant incident light even if the intensity is tiny.
\end{abstract}

Index Terms - optically triggered thyristor, simulation model, wavelength dependency, minimum intensity

\section{INTRODUCTION}

Silicon carbide $(\mathrm{SiC})$ is an attractive material for $S_{\text {manufacturing low on-resistance, high-voltage power }}$ devices. $\mathrm{SiC}$ thyristors are dedicated to the applications that exceed more than 10 MVA (megavolts-ampere) conversion power, especially high-voltage direct current (HVDC) electric power transmission system and power converters in smart grid [1-2]. This device already has been commercialized as engineering sample [3]. In the recent years, the $15-18 \mathrm{kV}$ class $\mathrm{SiC}$ light triggered thyristors, using $266 \mathrm{~nm}$ UV-C (Ultraviolet C) pulse laser, have been developed [4-5]. Dheilly et al. reported the demonstration of direct light triggering by 330-340 nm wavelength UV-A LEDs [6]. The main advantage of the optical gate driving provides galvanic isolation simplifying device driver circuitry, and it will contribute to realize the small thyristor with high reliability by preventing erroneous arc firing due to electromagnetic noise.

Compared to other power devices, designing thyristors are somewhat more challenging. The simulation model is essential to device design and circuit design. However, the facility of simulation convergence strongly depends on the meshing

"This paragraph of the first footnote will contain the date on which you submitted your paper for review. “ quality (structure discretization quality) and designers must face to the trade-off between the calculation cost and the convergence rate. It is difficult to calculate the thyristor characteristics due to the abundance of a number of layers. Therefore, few articles on the simulation modeling were published. Mnatsakanov et al. investigated the turn-on process based on the $18 \mathrm{kV}$ class thyristor simulation models [7]. Meyer et al. evaluated the resistance to inductive parasitic, using the circuit simulation including a thyristor with $250 \mathrm{~nm}$ wavelength optical source [8].

In this study, we developed the $10 \mathrm{kV}$ class $4 \mathrm{H}-\mathrm{SiC}$ optically triggered thyristor simulation model and evaluated the influences of the drift-layer lifetime $\tau_{\text {drift }}$ and incident light properties (wavelength $\lambda$ and intensity $I_{0}$ ) on the static and dynamical characteristics. The model accuracy was compared with experimental results.

\section{DEVICE STRUCTURE AND PHYSICAL MODELS}

The device was modeled thanks to Synopsys TCAD (Technological Computer Aided Design) Sentaurus ${ }^{\mathrm{TM}}$. The basic $4 \mathrm{H}-\mathrm{SiC}$ parameters were taken from the literature: dielectric constant [9], bandgap [10] and bulk mobility [11]. Incomplete ionization was ignored to simplify the model and improve the convergence in optical turn-on simulation.

\section{A. Device structure and optical source}

Several $10 \mathrm{kV}$ class $4 \mathrm{H}-\mathrm{SiC}$ optically triggered thyristors shown in Fig. 1 were fabricated for measuring the breakdown voltage and dynamical characteristics. The thyristors were

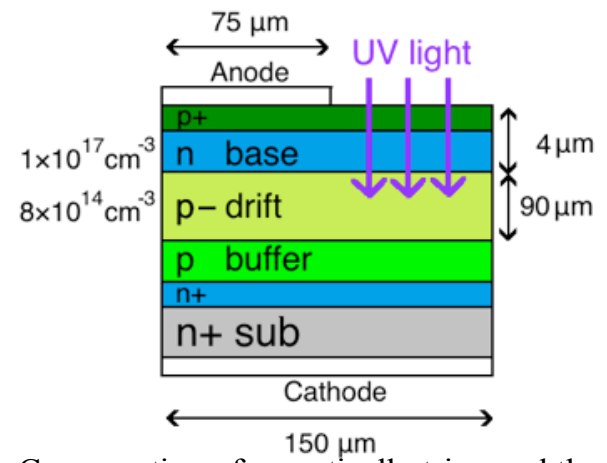

Fig. 1. Cross section of an optically triggered thyristor for measurering the breakdown voltage and dynamical characteristics. 
formed by a $\mathrm{p}^{-}$drift-layer which thickness is equal to $90 \mu \mathrm{m}$ and a thin $\mathrm{n}$ base-layer. The top of the device cells were formed by $\mathrm{p}+$ layer. We made circular holes in the anode electrode for optical gate (optical window). The $365 \mathrm{~nm}$ wavelength UV-A LEDs, which has advantages in term of the size and cost compared to UV-C laser, were used to turn-on.

In the simulation, the same structure was modeled in two dimensions and the anode current simulated by solving model equations in cylindrical coordinates. The center axis is the right side of device in Fig. 1. The sizes of optical window and anode electrode are $1.8 \times 10^{-4} \mathrm{~cm}^{2}$ and $5.3 \times 10^{-4} \mathrm{~cm}^{2}$, respectively. Area factor was set at 1.0. The monochromatic optical source was set to be uniformly irradiated to the optical windows.

\section{B. Lifetime}

The minority carrier lifetime is an important factor of bipolar device (forward characteristics of pin diode [12], turn-off characteristics of gate turn-off thyristor [13]). Variety p-type $\mathrm{SiC}$ lifetimes that are measured by the microwave photoconductance decay ( $\mu$-PCD) are reported: 0.1-1.6 $\mu$ s [14] and $10 \mu \mathrm{s}$ [15]. We defined the doping dependence of the lifetime by Scharfetter relation shown in eq. 1, and we dealt with $\tau_{\max }$ as a fitting parameter ( $\tau_{\text {drift }}$ is $\tau_{\max }$ at drift layer). $N_{\text {ref }}$ is set $3.0 \times 10^{17} \mathrm{~cm}^{-3}$ while $\gamma$ set 0.3 [16].

$$
\tau=\tau_{\max }\left\{1+\left(\frac{N_{\text {total }}}{N_{\text {ref }}}\right)^{\gamma}\right\}^{-1}
$$

\section{Avalanche Recombination}

Impact ionization coefficients are critical value for simulate the breakover voltage. Accordingly, the avalanche recombination model was considered. Variety fitting parameters are reported [17-24]. We used Niwa's parameter [23] based on Okuto-Crowell model [25] shown in eq. 2 (simplified by $T=300 \mathrm{~K}$ ). $\alpha$ is ionization coefficient, $E$ is field intensity, and $a, b, \delta$ are fitting parameters. The parameters for electrons are below: $a=8.19 \times 10^{9} \mathrm{~V}^{-1}, b=3.94 \times 10^{7} \mathrm{~V} / \mathrm{cm}$, and $\delta=1.0$.

$$
\alpha(E)=a \exp \left[-\left(\frac{b}{E}\right)^{\delta}\right]
$$

\section{Refractive index}

The penetration depth $\alpha^{-1}$ of light depends on imaginary part of complex refractive index (extinction coefficient $k$ ). Equation 3 shows the Beer-Lambert law. The intensity of an electromagnetic wave inside a material $I(z)$ fall off exponentially from the surface. Equation 4 is the relationship between penetration depth $\alpha^{-1}$ and extinction coefficient $k . \lambda$ is the wavelength of the light. The relationship between $\lambda$ and the absorption coefficient $\alpha$ were estimated [26] by using optical measurement result and the real part of complex refractive index $n$ of $6 \mathrm{H}-\mathrm{SiC}$ [27]. (Absorption coefficient $\alpha$ is a reciprocal of penetration depth $\alpha^{-1}$.) We used the real part of complex refractive index $n$ of $4 \mathrm{H}-\mathrm{SiC}$ in [28] and the imaginary part of complex refractive index $k$ was calculated from square root of the absorption coefficient $\alpha^{1 / 2}$. Fig. 2 shows the wavelength dependency of the penetration depth $\alpha^{-1}$, comparing the accurate value shown in [26] and our fitting to $\alpha^{1 / 2}-\lambda$ graph shown in same reference. In our fitting, $\alpha^{-1}$ is $126.6 \mathrm{~nm}$ at $365 \mathrm{~nm}$ wavelengths. It is enough to radiate the light to n-base layer.

$$
\begin{array}{r}
I(z)=I_{0} \exp [-\alpha z] \\
\alpha^{-1}=\frac{\lambda}{4 \pi k}
\end{array}
$$

\section{E. Quantum efficiency}

Quantum efficiency is the conversion efficiency from a photon to one electron hole pair. The step-function quantum yield model was used. This model is explained that the quantum yield is set to one when the excitation energy is greater than or equal to the bandgap energy, otherwise it is set to zero [29]. Nevertheless, some papers reported that the quantum efficiency regarding $365 \mathrm{~nm}$ wavelength laser radiation is $1 \%$ order. D. M. Brown, et al., showed the measurement results, analytical calculation results, and temperature dependency of quantum efficiency that were converted from the responsivity of $6 \mathrm{H}-\mathrm{SiC} \mathrm{n}^{+}-\mathrm{p}-\mathrm{p}^{+}$photodiode [30]. The value of $4 \mathrm{H}-\mathrm{SiC}$ Cr-SiC Schottky [31] and $p-n^{-}-n^{+}$ photodetector [32] are also reported. The indirect optical

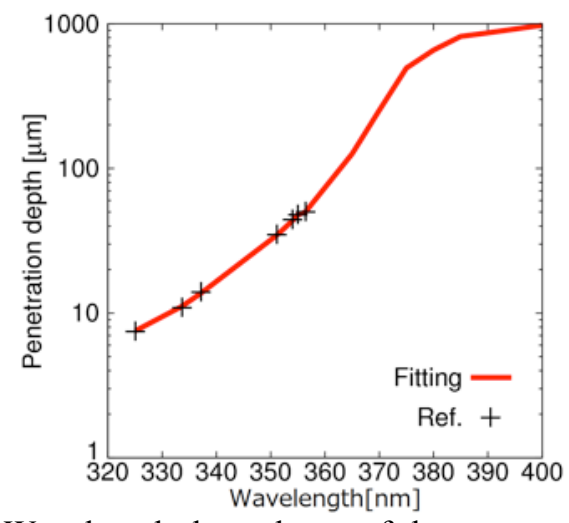

Fig. 2. Wavelength dependency of the penetration depth $\alpha^{-1}$. The cross-mark is the value shown in [26]. The red line is fitting from $\alpha^{1 / 2}-\lambda$ graph shown in same reference.

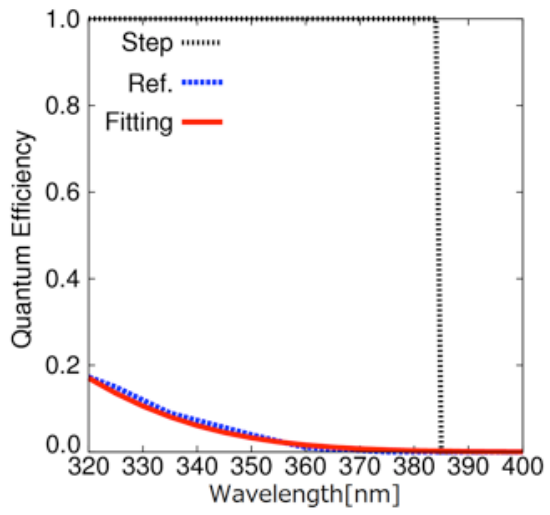

Fig. 3. Wavelength dependency of the quantum efficiency, comparing the value in [32], fitting result, and the step-function model. 
excitation occurs within the long wavelength $(295-385 \mathrm{~nm})$ and this excitation process is a reason of low quantum efficiency [31].

We changed the scaling factor (default is 1) of step-function model depending on each wavelength, to reproduce the realistic quantum efficiency. The quantum efficiency was varied from $1.1 \%(365 \mathrm{~nm})$ to $60 \%(265 \mathrm{~nm})$ with rough approximation by Gauss function. Fig. 3 shows the quantum efficiency, comparing the measurement value in [32] and our fitting. The value from step-function model with no scaling was also shown in Fig. 3.

\section{RESUlTS AND DisCUSSIONS}

We simulated both static and dynamic characteristics. To keep the correspondence with the actual static/dynamic characteristic measurement condition, the device temperature was kept at $300 \mathrm{~K}$ and a $500-\mathrm{k} \Omega$ series resistance had been introduced between the voltage source and the thyristor anode electrode. To avoid the capacitive displacement current that causes the undesired turn-on, the time change rate limit of voltage source was set at $1 \mathrm{~V} / \mathrm{s}$.

\section{A. The lifetime dependency of characteristics}

The static output characteristics $I_{\mathrm{a}}-V_{\text {ak }}$ were simulated and we estimated the lifetime dependency. Fig. 4(a) shows the simulated $I_{\mathrm{a}}-V_{\mathrm{ak}}$ characteristics. In this figure, the breakover voltage is $11 \mathrm{kV}$ and reverse breakdown voltage is $450 \mathrm{~V}$. The actual measured breakover voltage is $9.5 \mathrm{kV}$. The incomplete ionization and edge termination structure did not consider in this simulation. Those are one of the reasons of the difference between simulation and experimental results. (The simulated value considering incomplete ionization becomes $9.8 \mathrm{kV}$.) Fig. 4(b) shows the simulated optically turn-on and turn-off characteristics. The value of voltage source was swept from 0 $\mathrm{V}$ to $400 \mathrm{~V}$, and the strong incident light (intensity $I_{0}$ was 3800 $\mathrm{W} / \mathrm{cm}^{2}$, pulse duration $t_{\mathrm{d}}$ was $0.1 \mu \mathrm{s}$, turn-on/turn-off fronts was $1 \mathrm{~ns}$, and wavelength $\lambda$ was $365 \mathrm{~nm}$ ) was applied when the voltage become $300 \mathrm{~V}$ to turn-on. When we applied $300 \mathrm{~V}$, the $1 \mu \mathrm{m}$ order space-charge region appeared in the $\mathrm{n}$ base-layer caused by the reverse bias at $\mathrm{p}^{-}-\mathrm{n}$ junction. Turn-on occurred by the optical generated electron-hole pair, then, snap-back occurred ( $V_{\text {ak }}$ become lower even if we increased the value of voltage source from $300 \mathrm{~V}$ to $400 \mathrm{~V}$ ). Finally, the voltage decrease $400 \mathrm{~V}$ to $0 \mathrm{~V}$ to turn-off. When the anode current falls below the "holding current" due to reducing applied anode voltage, the turn-off process began. When the $\mathrm{p}^{-}$ drift-layer lifetime $\tau_{\text {drift }}$ was set at $0.4 \mu$ s for electrons, the holding current was $0.30 \mathrm{~mA}\left(0.57 \mathrm{~A} / \mathrm{cm}^{2}\right)$, and the holding voltage was $3.1 \mathrm{~V}$. The on-state voltage once the device has been fully turned-on were 3.05-3.11 V in Fig. 4, and these simulated values fit well with experimental data.

Fig. 5 shows the comparison between the simulated holding current and the experimental result. The holding current reduced by half when the lifetime varied from 0.40 to $0.50 \mu$ s. Some papers discussed the relationship between the holding current of $4 \mathrm{H}-\mathrm{SiC}$ thyristor and the lifetime [33-34]. The $\mathrm{n}$ base-layer minority carrier concentration, which contributes to keeping on-state and decides the value of holding current, is controlled by the lifetime. The measured holding current was $0.38 \mathrm{~mA}\left(0.72 \mathrm{~A} / \mathrm{cm}^{2}\right)$, and the simulation reproduced this value well when we use $\tau_{\text {drift }}=0.4 \mu \mathrm{s}$. We applied this value in the simulation as a rough estimation instead of the result of lifetime measurement methods that are represented by $\mu$-PCD. In addition, we also simulated the lifetime dependency of breakover voltage. The breakover voltage had no significant lifetime dependency.

Fig. 6 shows the simulated $I_{\mathrm{a}}-t$ characteristics when the turn-on process occurred by the incident light. The time axis shows the elapsed time after the optical pulse kick-started. $V_{\mathrm{ak}}$
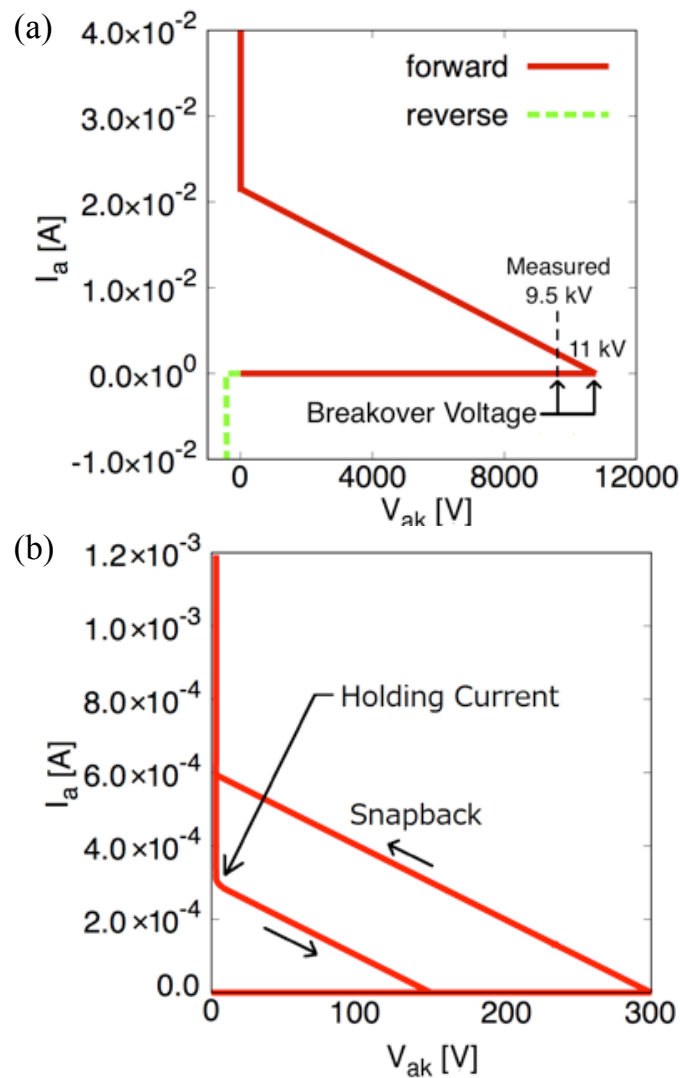

Fig. 4. Output characteristic simulation results (a) without incident light (b) with incident light $\left(I_{0}=3800\right.$ $\mathrm{W} / \mathrm{cm}^{2}$, duration is $0.1 \mu \mathrm{s}$ ) at $V_{\mathrm{ak}}=300 \mathrm{~V}$.

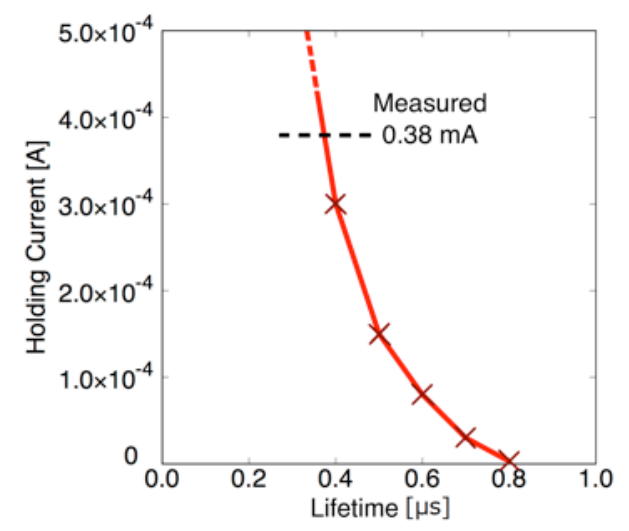

Fig. 5. Holding current simulation result. The applied voltage decrease $400 \mathrm{~V}$ to $0 \mathrm{~V}$ to turn-off. An experimental result is also shown. 


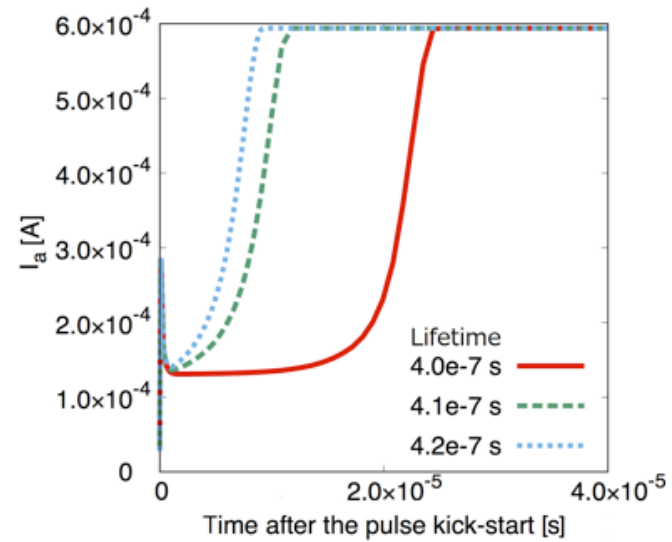

Fig. 6. Simulation result of $I--t$ characteristics with variety lifetime. $V_{\text {ak }}$ is $300 \mathrm{~V}$. The incident light intensity is $3800 \mathrm{~W} / \mathrm{cm}^{2}$ and duration is $0.1 \mu \mathrm{s}$. The horizontal axis shows the elapsed time after starting the light irradiation.

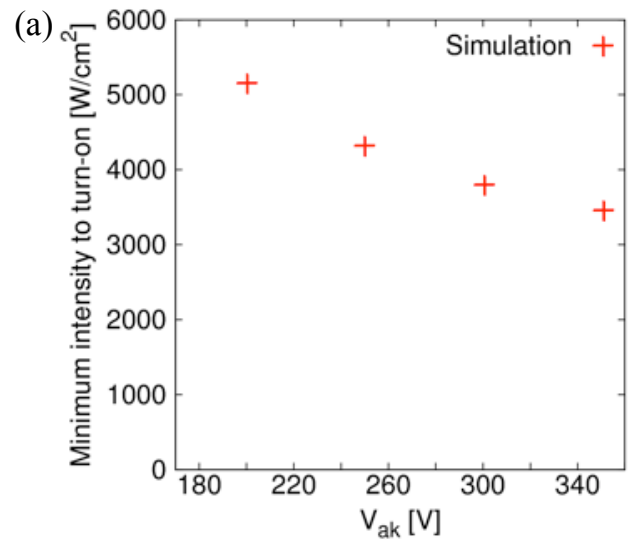

(b)

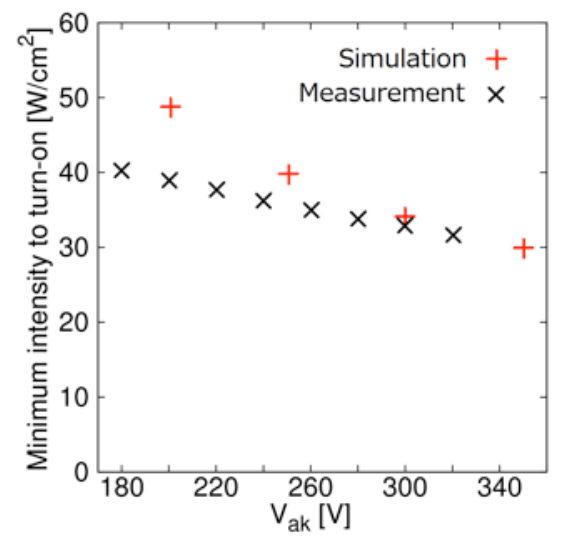

Fig. 7. Minimum intensity of optical pulse to turn-on. The pulse duration is set at (a) $0.1 \mu \mathrm{s}$ (b) $15.4 \mu \mathrm{s}$. The wavelength is $365 \mathrm{~nm}$.

was set at $300 \mathrm{~V}$ and the same strong incident light with Fig 4(b) was used: $I_{0}=3800 \mathrm{~W} / \mathrm{cm}^{2}, t_{\mathrm{d}}=0.1 \mu \mathrm{s}$, and $\lambda=365 \mathrm{~nm}$. We also showed the lifetime dependency of the turn-on time in Fig. 6. The lifetime varied from $\tau_{\text {drift }}=0.40 \mu \mathrm{s}$ to $0.42 \mu \mathrm{s}$. The initial current spike coming from the initial carrier optical generation [7, 35]. The turn-on time is $23 \mu$ s when $\tau_{\text {drift }}=0.40$ $\mu \mathrm{s}$. Comparing between $\tau_{\text {drift }}=0.40 \mu$ s and $\tau_{\text {drift }}=0.41 \mu \mathrm{s}$, the turn-on time reduced by half even if the lifetime extended only 10 ns. This result shows the importance of the controlling balance between carrier generation and recombination to start the turn-on fast. Note that the long lifetime increases the minority carrier in the drift layer, which cause the tail current.

\section{B. Light irradiation response}

The minimum optical power required to trigger the thyristor is an important factor to reduce the energy loss of the thyristor upon turn-on. Fig. 7 shows the simulated minimum incident light illumination intensity to turn-on, $I_{0 \mathrm{~min}}$ at $V_{\mathrm{ak}}=200-350 \mathrm{~V}$. The wavelength $\lambda$ was $365 \mathrm{~nm}$ and the pulse duration $t_{\mathrm{d}}$ was set at (a) $0.1 \mu \mathrm{s}$ and (b) $15.4 \mu \mathrm{s}$. We also measured $I_{0 \min }$ using $\lambda=365 \mathrm{~nm}$ UV-A LED. $t_{\mathrm{d}}$ was set at $15.4 \mu \mathrm{s}$. The values of intensity, which are incident optical power density at the surface of optical window, were estimated from the LED current and the spatial arrangement of LEDs. Comparing with experimental results shown in Fig. 7(b), the simulation obtained well results closer to actual value in the range of $V_{\mathrm{ak}}$ $=300-350 \mathrm{~V}$. The simulated value was $I_{0 \min }=34.0 \mathrm{~W} / \mathrm{cm}^{2}$, and measured value was $I_{0 \min }=32.9 \mathrm{~W} / \mathrm{cm}^{2}$ at $V_{\text {ak }}=300 \mathrm{~V}$. According to Fig. 7, I0min become lower when the applied voltage become higher. The electric field originated in $V_{\mathrm{ak}}$ helps the injection of the optically generated hole carriers from $\mathrm{p}+$ emitter to thin $\mathrm{n}$-base and wide $\mathrm{p}$-drift region. Then the total amount of photo-generated hole which necessary to turn-on are decreased by the carrier injection rate increasing. This explains the relationship between $I_{0 \min }$ and $V_{\text {ak. }}$ On the other hand, The multiple value of $t_{\mathrm{d}}$ and $I_{0 \min }$ is about $5 \mathrm{~W} \cdot$ $\mathrm{s} / \mathrm{m}^{2}$ at $V_{\mathrm{ak}}=300 \mathrm{~V}$ even if the $t_{\mathrm{d}}$ was extended more than 100 times. This constant shows the rough relationship between $t_{\mathrm{d}}$ and $I_{0 \mathrm{~min}}$. We notice that we used the ideal light source and ignored the time dependence of the intensity in this simulation.

The wavelength dependency of $I_{0 \mathrm{~min}}$ is salient than the applied voltage dependency. Fig. 8 shows the wavelength dependence of $I_{0 \mathrm{~min}}$. The wavelength was set within a range of $\lambda=325-400 \mathrm{~nm}$, and only one-photon excitation phenomena was considered in the simulation model. The applied voltage was $V_{\mathrm{ak}}=300 \mathrm{~V}$ and pulse duration was $t_{\mathrm{d}}=15.4 \mu \mathrm{s}$. The experimental result with $\lambda=365 \mathrm{~nm}$ was also shown in this figure (same value as Fig. 7(b)). According to simulation result in Fig. 8, $I_{0 \text { min }}$ become less than 0.003 times when the wavelength changed from $380 \mathrm{~nm}$ to $325 \mathrm{~nm}$. The turn-on process did not occur at $\lambda>385 \mathrm{~nm}$ wavelength. In our measurement, the turn-on phenomena also not occur in $\lambda=$ $400 \mathrm{~nm}$. These tendencies can be explained by considering three phenomena:

- The quantum efficiency is large at short wavelength. In our parameter, shown in Fig. 3, the quantum efficiency is $0.31 \%$ at $380 \mathrm{~nm}, 1.1 \%$ at $365 \mathrm{~nm}$ and $14 \%$ at 325 $\mathrm{nm}$. This wavelength dependency is the main reason of the significant $I_{\text {min }}$ wavelength dependency. The quantum efficiency is directly related to the quantity of photo-excited non-equilibrium carriers. If the amount of these carriers is larger than the "critical charge", the turn-on finally occurs [7].

- The penetration depth steeply decreases at short wavelength. According to Fig. 2, the penetration depth is $126 \mu \mathrm{m}$ at $\lambda=365 \mathrm{~nm}$, and $7.25 \mu \mathrm{m}$ at $\lambda=325 \mathrm{~nm}$. 


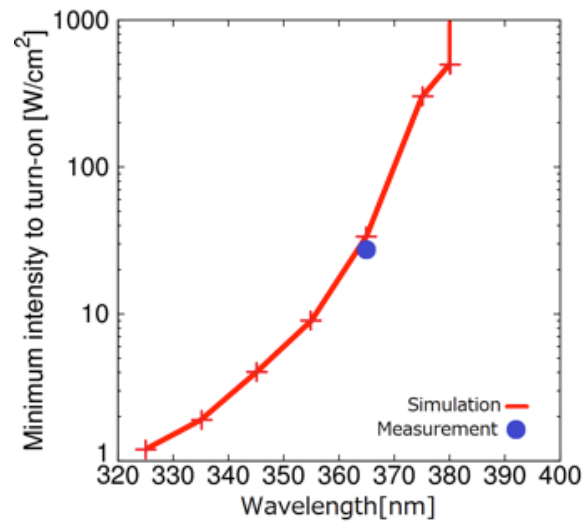

Fig. 8. Wavelength dependency of the minimum intensity to turn-on. An experimental result is also shown by blue dot. The pulse duration is set at $15.4 \mu \mathrm{s}$.

However, due to the anode $\mathrm{p}^{+}$layer and the $\mathrm{n}$ base layer are thin, this wavelength dependency does not affect to $I_{0 \min }$ in a range of $\lambda>325 \mathrm{~nm}$.

- Excitation energy is not enough at $\lambda>385 \mathrm{~nm}$, hence, there is no way to excite the carriers even if the intensity is strong. The energy of a photon $h c / \lambda$ is 3.22 $\mathrm{eV}$ at $385 \mathrm{~nm}$, and the $4 \mathrm{H}-\mathrm{SiC}$ bandgap $E_{\mathrm{g}}$ is $3.23 \mathrm{eV}$ at $300 \mathrm{~K}$ [10]. The Franz--Keldysh effect was not considered in our simulation. This effect will affect the long-wavelength side limit [36].

In addition, we simulated the lifetime dependency of $I_{0 \mathrm{~min}}$. The lifetime has no significant effect to decide $I_{0 \mathrm{~min}}$.

The low intensity UV-A light has no influence on turn-on. However, it negatively affects the breakover voltage. Fig. 9 shows the simulated wavelength dependency of breakover voltage. The constant weak incident light always irradiated (not pulsed) and others simulation conditions are same as Fig. 4(a). The light intensity $I_{0}$ varied in the range of $0.1-10$ $\mu \mathrm{W} / \mathrm{cm}^{2}$, and this intensity is less than $1 / 1,000,000$ times of $I_{0 \min }$ that was shown in Fig. 7(b). Note that the UV-A emission from fluorescent lamp at a distance of $20 \mathrm{~cm}$ is $I_{0}=10$ $\mu \mathrm{W} / \mathrm{cm}^{2}$ order [37]. When we applied the light with $\lambda>385$ $\mathrm{nm}\left(h c / \lambda<E_{\mathrm{g}}\right)$, the breakover voltage was not changed by UV-A light $(11 \mathrm{kV})$. However, in the case of the $\lambda=360 \mathrm{~nm}$, the breakover voltage became $8.9 \mathrm{kV}$ under the $I_{0}=0.1$ $\mu \mathrm{W} / \mathrm{cm}^{2}$. Moreover, the thyristor almost lost the blocking ability in the range of $\lambda<360 \mathrm{~nm}$ when $I_{0}=10 \mu \mathrm{W} / \mathrm{cm}^{2}$. These results show the importance of the UV light shielding.

In this study, all the dynamic calculations are made for the voltage of $400 \mathrm{~V}$ for the purpose of comparing with the experimental results. To modeling and discuss the turn-on operation in higher voltage, the model should be checked the correctness considering the large current density and the experimental evidence of sensitivity to incident light.

\section{CONCLUSIONS}

We developed the $10 \mathrm{kV}$ class $4 \mathrm{H}-\mathrm{SiC}$ optically triggered thyristor simulation model, and we evaluated the influence of the drift-layer lifetime $\tau_{\text {drift }}$ and incident light properties (wavelength $\lambda$ and intensity $I_{0}$ ) on the static and dynamical characteristics. The model accuracy, especially the holding

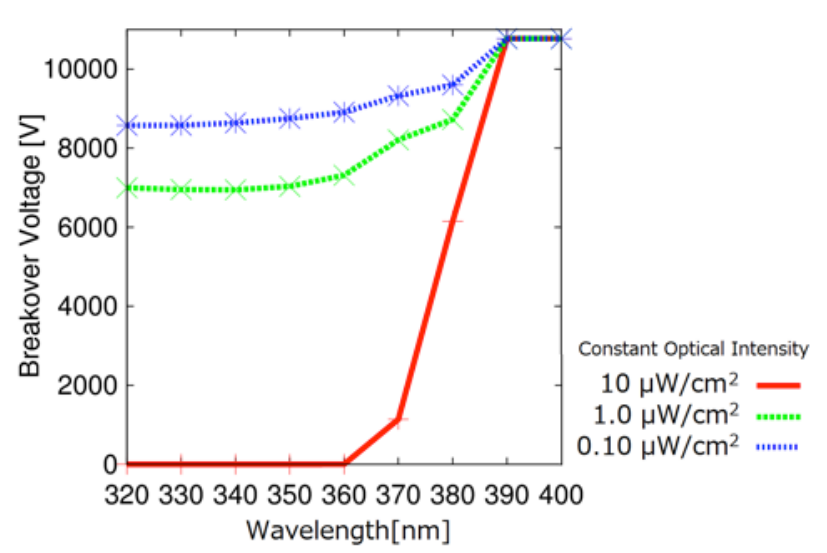

Fig. 9. Wavelength dependency simulation result of the breakover voltage. The slope of applied voltage is 1 $\mathrm{V} / \mathrm{s}$. The incident light irradiated constant.

current and the minimum incident light intensity to turn-on, was compared with experimental results.

The holding current and turn-on time depends on the lifetime. In our simulation, the holding current reduced by half when the lifetime varied from 0.40 to $0.50 \mu \mathrm{s}$, and the turn-on time reduced by half when the lifetime varied from 0.40 to $0.41 \mu \mathrm{s}$. The minimum incident light intensity to turn-on $I_{0 \mathrm{~min}}$ significantly depends on the incident light wavelength. The measured $I_{0 \min }$ is $32.9 \mathrm{~W} / \mathrm{cm}^{2}$ at the pulse duration $15.4 \mu \mathrm{s}, V_{\mathrm{ak}}$ $=300 \mathrm{~V}$. And the simulation reproduced the experimental result well. In our simulation, $I_{0 \min }$ become less than 0.003 times when the wavelength changed from $380 \mathrm{~nm}$ to $325 \mathrm{~nm}$, due to the wavelength dependency of the quantum efficiency. On the other hand, the low intensity UV-A light has no influence to turn-on, however, it is affect to breakover voltage degradation.

\section{REFERENCES}

[1] A. Agarwal, Q. J. Zhang, A. Burk, R. Callanan and S. Mazumder "Prospects of bipolar power devices in silicon carbide" Presented at IECON 2008 Annual Conference, 2879-2884.

[2] T. P. Chow "Progress in high voltage $\mathrm{SiC}$ and $\mathrm{GaN}$ power switching devices" Mater. Sci. Forum, 778-780 (2014) 1077-1082.

[3] GeneSiC Semiconductor, "SiC Ultra High Voltage PiN Rectifiers and Thyristors," GeneSiC Semiconductor, 2014. [Online]. Available: http://www.genesicsemi.com/commercial-sic/sic-ultra-high-voltage-pinthyristors/. Accessed: Jan. 30, 2017.

[4] S. L. Rumyantsev, M. E. Levinshtein, M. S. Shur, L. Cheng, A. K. Agarwal and J. W. Palmour "Optical triggering of high-voltage (18 kV-class) 4H-SiC thyristors" Semicond. Sci. Tech., 28 (2013) 125017-125020.

[5] A. Mojab, S. K. Mazumder, L. Cheng, A. K. Agarwal and C. J. Scozzie "15-kV single-bias all-optical ETO thyristor" Presented at ISPSD 2014, 313-316.

[6] N. Dheilly, G. Pâques, S. Scharnholz, P. Bevilacqua, C. Raynaud, D. -M. Nguyen, R. W. De Doncker and D. Planson "Optical triggering of SiC thyristors using UV LEDs" Electronics Letters, 48 (2011) 459-460.

[7] T. T. Mnatsakanov, S. N. Yurkov, M. E. Levinshtein, L. Cheng and J. W. Palmour "Specific features of switch-on processes in high-voltage (18 kV class) optically triggered $4 \mathrm{H}-\mathrm{SiC}$ thyristors" Semicond. Sci. Tech., 29 (2014) 055005.

[8] A. Meyer, A. Mojab and S. K. Mazumder "Evaluation of first 10-kV optical ETO thyristor operating without any low-voltage control bias" Presented at PEDG 2013, 1-5.

[9] L. Patrick and W. J. Choyke "Static Dielectric Constant of SiC" Physical Review B, 2 (1970) 2255-2256. 
[10] Y. Goldberg, M. E. Levinshtein and S. L. Rumyantsev "Properties of Advanced Semiconductor Materials GaN, AlN, SiC, BN, SiC, SiGe" John Wiley \& Sons, Inc., New York (2001) 93-148.

[11] T. Ayalew "SiC Semiconductor Devices, Technology, Modeling, and Simulation" Ph.D.thesis, Faculty of Electrical Engineering and Information, Technology, Technishen Universitaet Wien, Austria, 2004.

[12] A. A. Ogunniyi, H. K. O’Brien, M. Hinojosa, L. Cheng, C. J. Scozzie, B. N. Pushpakaran, S. Lacouture and S. B. Bayne "Analysis of carrier lifetime effects on HV SIC PiN diodes at elevated pulsed switching conditions" Presented at PPC 2015, 1-6.

[13] S. Sundaresan and R. Singh "Comparison of Turn-Off Strategies for SiC Thyristors" Mater. Sci. Forum, 821-823 (2015) 889-892

[14] T. Hayashi, K. Asano, J. Suda and T. Kimoto "Enhancement and control of carrier lifetimes in p-type 4H-SiC epilayers" J. Appl. Phys., 112.6 (2012) 064503.

[15] T. Okuda, T. Miyazawa, H. Tsuchida, T. Kimoto and J. Suda "Enhancement of carrier lifetime in lightly Al-doped p-type 4H-SiC epitaxial layers by combination of thermal oxidation and hydrogen annealing" Appl. Phys. Express, 7 (2014) 085501.

[16] M. Ruff, H. Mitlehner and R. Helbig "SiC devices: physics and numerical simulation" IEEE Trans. on Electron Devices, 41 (1994) 1040-1054.

[17] R. Raghunathan and B. J. Baliga "Measurement of electron and hole impact ionization coefficients for SiC" Presented at ISPSD1997, 173-176.

[18] A. O. Konstantinov, Q. Wahab, N. Nordell and U. Lindefelt "Ionization rates and critical fields in $4 \mathrm{H}$ silicon carbide" Appl. Phys. Lett. 71.1 (1997) 90.

[19] T. Hatakeyama, T. Watanabe, T. Shinohe, K. Kojima, K. Arai and N. Sano "Impact ionization coefficients of $4 \mathrm{H}$ silicon carbide" Appl. Phys. Lett. 85.8 (2004) 1380

[20] W. S. Loh, B. K. Ng, J. S. Ng, S. I. Soloviev, H. -Y. Cha, P. M. Sandvik, C. M. Johnson and J. P. R. David "Impact Ionization Coefficients in 4H-SiC" IEEE Trans. on Electron Devices, 55.8 (2008) 1984-1990.

[21] D. M. Nguyen, C. Raynaud, N. Dheilly, M. Lazar, D. Tournier, P. Brosselard and D. Planson "Experimental determination of impact ionization coefficients in 4H-SiC" Diam. Relat. Mater. 20.3 (2011) 395-397.

[22] J. E. Green, W. S. Loh, A. R. J. Marshall, B. K. Ng, R. C. Tozer, J. P. R. David, S. I. Soloviev and P. M. Sandvik "Impact Ionization Coefficients in 4H-SiC by Ultralow Excess Noise Measurement" IEEE Trans. on Electron Devices, 59.4 (2012) 1030-1036.

[23] H. Niwa, J. Suda and T. Kimoto "Temperature Dependence of Impact Ionization Coefficients in 4H-SiC" Mater. Sci.Forum, 778-780 (2014) 461-466.

[24] H. Niwa, J. Suda and T. Kimoto "Impact Ionization Coefficients in 4H-SiC Toward Ultrahigh-Voltage Power Devices" IEEE Trans. on Electron Devices, 62.10 (2015) 3326-3333.

[25] Y. Okuto and C. R. Crowell "Threshold energy effect on avalanche breakdown voltage in semiconductor junctions" Solid-State Electron. 18.2 (1975) 161-168.

[26] S. G. Sridhara, T. J. Eperjesi, R. P. Devaty and W. J. Choyke "Penetration depths in the ultraviolet for $4 \mathrm{H}, 6 \mathrm{H}$ and $3 \mathrm{C}$ silicon carbide at seven common laser pumping wavelength" Mater. Sci. Eng. B, 61 (1999) 229-233.

[27] W. J. Choyke and L. Patrick "Refractive Index and Low-Frequency Dielectric Constant of 6H SiC" J. Opt. Soc. Am., 58.3 (1968) 377-379

[28] K. -S. Park, T. Kimoto and H. Matsunami "High Quantum-Efficiency 4H-SiC UV Photodiode" J. Korean Phys. Soc., 30.1 (1997) 123-130

[29] Synopsys.Inc. "Sentaurus ${ }^{\mathrm{TM}}$ Device User Guide" Version J-2014.09 (2014)

[30] D. M. Brown, E. T. Downey, M. Ghezzo, J. W. Kretchmer, R. J. Saia, Y. S. Liu, J. A. Edmond, G. Gati, J. M. Pimbley and W. E. Schneider "Silicon carbide UV photodiodes" IEEE Trans. on Electron Devices, 40 (1993) 325-333.

[31] T. V. Blank, Y. A. Goldberg, E. V. Kalinina, O. V. Konstantinov, A. O. Konstantinov and A. Hallén "Temperature dependence of the photoelectric conversion quantum efficiency of $4 \mathrm{H}-\mathrm{SiC}$ Schottky UV photodetectors" Semicond. Sci. and Tech., 20 (2005) 710-715

[32] A. V. Sampath, L. E. Rodak, Y. Chen, Q. Zhou, J. C. Campbell, H. Shen and M. Wraback "High quantum efficiency deep ultraviolet $4 \mathrm{H}-\mathrm{SiC}$ photodetectors" Electronics Letters, 49.25 (2013) 1629-1630.

[33] P. B. Shah and K. A. Jones "Two-dimensional numerical investigation of the impact of material-parameter uncertainty on the steady-state performance of passivated 4H-SiC thyristors" J. Appl. Phys., 84.8 (1998) 4625.

[34] S. Solovieva, A. Elasser, S. Katz, S. Arthur, Z. Stum and L. Yu "Optimization of Holding Current in $4 \mathrm{H}-\mathrm{SiC}$ Thyristors" Mater. Sci. Forum, 740-742 (2013) 994-997

[35] M. E. Levinshtein, P. A. Ivanov, A. K. Agarwal and J. W. Palmour "Optical switch-on of silicon carbide thyristor" Electronics Letters, 38.12 (2002) 592-593.

[36] F. Yan, C. Qin, J. H. Zhao, M. Weiner, B. K. Ng, J. P. R. David and R. C. Tozer "Low-noise visible-blind UV avalanche photodiodes with edge terminated by $2^{\circ}$ positive bevel" Electronics Lett. 38.7 (2002) 1

[37] S. Miller, R. Bergman, M. Duffy, D. Gross, A. Jackson, R. James, M. Kotrebai, A. Lamontagne, T. Lyon, E. Yandek and D. Sliney "Inter laboratory Evaluation of Ultraviolet Radiation Emissions from Compact Fluorescent Lamps" Photochem. Photobiol., 92.2 (2016) 348-354.

Junichi Hasegawa: received the B.S. degree in physics from Chuo University, Tokyo, Japan, in 2012, and the M.S. degree in electronic engineering from the Tokyo Institute of Technology, Tokyo, in 2014, where he is currently pursuing the Ph.D. degree.

Loris Pace: was born in Altkirch, France, in 1992. He received the Dipl.Ing. degree in electrical engineering from INSA Strasbourg, Strasbourg, France, in 2015. He joined the Ampère Laboratory, Lyon, France, in 2015. He was involved in the characterization of optical $\mathrm{SiC}$ high-power thyristors using UV LEDs and the implementation of these devices in $\mathrm{DC} / \mathrm{DC}$ converters.

Luong Viêt Phung: was born in Blois, France, in 1983. He received the M.Sc. degree in electronic engineering and the Ph.D. degree in solid-state electronics from the University of Tours, Tours, France, in 2006 and 2010, respectively. In 2011, he joined the Ampère Laboratory, Lyon, France, as an Associate Professor.

Mutsuko Hatano: received a doctor of engineering degree from Keio University in Tokyo. She joined Central Research Laboratory, Hitachi Ltd. and was engaged in research and development on the superconducting devices, low-power devices and mobile displays. She was a chief researcher and a head of the environment electronics project at the CRL. In 2010, she joined the Tokyo Institute of Technology as a Professor with the Department of Electrical and Electronic Engineering.

Dominique Planson: was born in Paris, France, in 1965. He received the Dipl.Ing. degree in electrical engineering and the Ph.D. degree from INSA de Lyon, Villeurbanne, France, in 1991 and 1994, respectively. In 1994, he joined the Ampère Laboratory, Lyon, France, as an Assistant Professor. Since 2006, he has been a Professor and supervises the Power Electronics and Integration research activities with the Ampère Laboratory. 